\title{
Görme Engelli Bireyler İçin Derin Öğrenme Tabanlı Nesne Tanıma Modeli
}

\author{
İsa Avc1 ${ }^{1 *}$, Mehmet Yıldırım ${ }^{2}$ \\ $\mathbf{1}^{*}$ Karabuk Üniversitesi, Mühendislik Fakültesi, Bilgisayar Bölümü, İstanbul, Türkiye (ORCID: 0000-0001-7032-8018), isaavci@karabuk.edu.tr \\ 2 Karabuk Üniversitesi, Mühendislik Fakültesi, Bilgisayar Bölümü, İstanbul, Türkiye (ORCID: 0000-0001-7094-9658), myildirim@ogrenci.karabuk.edu.tr
}

(1st International Conference on Applied Engineering and Natural Sciences ICAENS 2021, November 1-3, 2021)

(DOI: $10.31590 /$ ejosat.995726)

ATIF/REFERENCE: Avcı, İ. \& Yıldırım, M. (2021). Görme Engelli Bireyler İçin Derin Öğrenme Tabanlı Nesne Tanıma Modeli. Avrupa Bilim ve Teknoloji Dergisi, (28), 220-227.

\section{Öz}

Görme engelli bireylerin sayısı her geçen gün artmaktadır ve Türkiye nüfusu içinde görme engelli oranı \%0,3’ tür. Görme engelli bireyler fiziksel erişilebilirlik sorunları ve teknolojinin yeterince onlara uygun şekilde gelişim gösterememesi gibi nedenlerden dolayı sosyal yaşamda çok fazla yer alamamaktadırlar. Görme engelli bireylerin yaşam kalitesini arttırmak ve sosyal yaşam olanağı sağlamak amacıyla, yanı başlarında yardımcı olacak bu uygulama ile onlara günlük hayatta kolaylık sağlayacak ve bu bireylerin yaşam açısından zevk almaları sağlanacaktır. Bu çalışma, görme engelli bireyler için göz olacak ve etrafındaki nesneleri, uygulama sayesinde ve kamera aracılığıyla görüntüleyebileceklerdir. Ayrıca seslendirmeler sayesinde onlar için etraflarında nelerin olduğu konusunda farkındalıkları artacaktır. Seslendirdiği yön ve gördüğü nesneler sayesinde kişinin ne yapacağı, hangi tarafa yönleneceği hakkında bilgi sahibi olması sağlanmış olacaktır. Böylelikle bu bireyler yalnız başlarına dışarı çıkıp dolaşma kolaylığına sahip olacaklardır. Bu çalışma da, açık kaynak kodlu yapay sinir ağı kütüphanesi olan Darknet kütüphanesi kullanılıp, nesne tespiti yapmak için YOLO algoritmasının önceden eğitilmiş modeli kullanılmıştır. Bilgisayar ortamında işlem yapılması için, QT Designer programı ile kullanıcı ara yüzü tasarlanmıştır. Önerilen bu modelde 81 adet nesnenin yapay sinir ağı modeli ile eğitimi yapılarak, nesneleri tanıması gerçekleştirilmiştir. Bu çalışmada, görme engelli bireyler için derin öğrenme tabanlı nesne tanıma modeli önerilmiştir.

Anahtar Kelimeler: Bilgisayarlı Görme Teknikleri, YOLO Algoritması, Görme Engelli Bireyler, Derin Öğrenme, Gerçek Zamanlı Nesne Tanıma.

\section{Deep Learning-Based Object Recognition Model For Visually Impaired Individuals}

\begin{abstract}
The number of visually impaired individuals is increasing day by day and the rate of visually impaired in Turkey's population is $0.3 \%$. Visually impaired individuals cannot take part in social life very much in terms of social relations due to reasons such as physical accessibility problems and the insufficient development of technology. This application, which will help visually impaired individuals with the aim of increasing their quality of life and providing social life opportunities, will provide convenience in their daily life and ensure that these individuals are happy in terms of life. This work will be an eye for visually impaired individuals and they will be able to view the objects around them through the application and the camera. In addition, thanks to the voice-overs, their awareness of what is around them will increase. Thanks to the direction he voices and the objects he sees, it will be ensured that the person has information about what to do and which way to go. In this way, these individuals will have the convenience of going out and wandering alone. In this study, the Darknet library, which is an open-source artificial neural network library, was used and a pre-trained model of the YOLO algorithm was used to detect objects. The user interface was designed with the Qt Designer program for processing in the computer environment. In this proposed model, 81 objects were trained with the artificial neural network model and the objects were recognized. In this study, a deep learning-based object recognition model is proposed for visually impaired individuals.
\end{abstract}

Keywords: Computer Vision Techniques, Yolo Algorithm, Visually Impaired Individuals, Deep Learning, Real-Time Object Recognition.

\footnotetext{
* Sorumlu Yazar: isaavci@karabuk.edu.tr
} 


\section{Giriş}

Bilindiği üzere dünyada olan olayları, çevredeki değişen ortamları görmeyi sağlayan organ gözdür. Göz organında, kişinin elinde olmayan sebeplerden dolayı sağlık sorunları ortaya çıkmaktadır ve bu sorunlar kalıcı hasar olarak baş göstermektedir. Beş duyu organdan biri olan göz, bilinenlerin, duyulanların hatta hissedilenlerin \%80' ini öğrenmeyi sağlayan organdır. Görme engelli bir kişi ile sohbet etme şansınız olduysa, onların en büyük üzüntüsünün gözlerinin görmemesi değil, etrafındaki insanların merhametsiz ve yardımsever olmamasıdır. Toplum genelinin görme engelli bireylere karşı hoşgörülü olmamaları, onların hayatlarını kolaylaştıracak herhangi bir fiili de gerçekleştirmemelerine sebep olmamaktadır.

Dünya da yaklaşık 1,3 milyar kişinin, görme bozukluğu sorunu bulunmaktadır. $\mathrm{Bu}$ kişilerin de 36 milyon kadarı görmeyi tamamen kaybetmiş bireylerdir (WHO, 2021). Görme engelli bireyler, yaşadıkları çevrede kendilerinin yapmakla yükümlü oldukları işleri herhangi bir yardım almadan yapabilseler, diğer sağlıklı insanlar gibi eşit olanaklara sahip olsalar, yaşadıkları bu hayatta dışlanmamış olacaklardır. Bu da hayatlarından hep zevk almalarını sağlayacaktır. Kendi işlerini başkalarının yardım etmesine gerek kalmadan ve başka insanlara yük olduğunu düşünmeden halletmek onları çok mutlu edecektir. Ülkemizde görme engelli bireylerin isteklerinden bazıları, diğer sağlıklı bireylerle eşit hak ve olanaklara sahip olmak, toplumda daha çok vakit geçirmek, günlük yaşantılarında başka insanların yardımına ihtiyaç duymamak ve daha rahat olabilecekleri şartlara sahip olmaktır.

Hali hazırda bulunan normal eğitim sistemindeki bu ortamların eşit koşullarda olmaması, yararları bakımından tartışmaya açık bir sistemdir. Bu eğitim sisteminde devletin gerekli desteği gösteremediği ve gerekli önlemlerin alınmadığı belirtilmektedir. Örneğin Braille (körler) alfabesini, ilkokula yeni başlayan bir kişinin öğretmeni ile bir haftada yaklaşık 2 saat gibi bir sürede öğrenilebileceği düşünülmektedir. Fakat bu eğitimin de düzenli olarak verilemediği vurgulanmıştır. Buradaki sorunlardan biri de eğitmenlerin engelli öğrencilere nasıl ders vereceklerini bilememeleri olup, bunun da ciddi sorunlara sebep olabilmesidir. Turged Derneğine göre, bu eğitim-öğretimdeki sıkıntılar nedeniyle görme engellilerin zorlandığı derslerden biri olan matematik dersinde başarılı olma ihtimallerinin çok fazla olmadığı dile getirilmiştir. Bu çalışmada nesneler seslendirildiği için bu konu da görme engelli bireylere kolaylık sağlayacaktır (Veri Gazeteciliği, 2021).

Toplumda, görme engelli bireylerin kendi başlarına kimseye ihtiyacı olmadan bir yerden başka bir yere gitmeleri mümkün olabilmektedir. Görme engelli bireylerin yanlarında eşlik edecek kimsesi yoksa metalden yapılmış olan beyaz renkli bastonları vardır. Bu baston ile etrafındaki nesnelere çarpmadan gitmeyi sağlarlar ve bu baston katlanabilir özelliğe sahiptir.

Görme engelli bireylerin yaşantılarında, eğitimlerinde veya çalışma alanlarında, onlar için tasarlanmış araçlar bulunmaktadır. Bunları söyleyecek olursak; termometreler, kabartmalı noktalarla gösterilen rakamlara sahip saatler, kan şekerini ve tansiyonu ölçen aletler, yapılan hesabı seslendiren hesap makineleri, sesli olarak renkleri ne olduğunu söyleyen cihazlar, rakamları kabartmalı paralar, kişisel bilgisayarlar, özel gözlükler, büyüteçler, mutfak aletleri görme engelli bireylerin günlük yaşantılarında fayda sağlayan nesnelerdir. $\mathrm{Bu}$ nesnelerin çoğu yurt dışından getirilmektedir. Artık ülke olarak, sosyal bilince sahip olup, görme engelli bireylerin yaşadıklarını ve onları da bu güzel dünyaya dâhil etmek için elinden gelen her imkânı sağlamaya çalışılmaktadır (MKA, 2021).

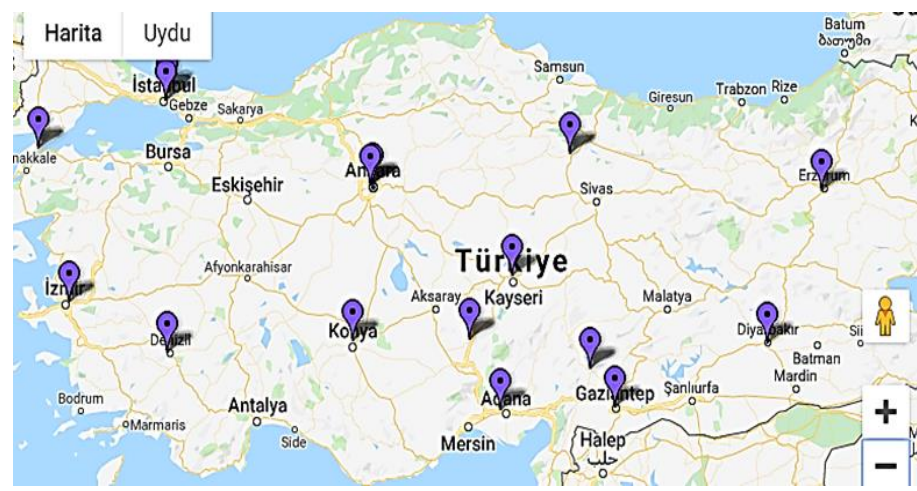

Şekil 1. Türkiye Görme Engelli Dağılım Haritası.

Aile, Çalışma ve Sosyal Hizmetler Bakanlığı'nın 2011 yılında yapmış olduğu çalışmaya göre, Türkiye nüfusunun \%1,4' ü yani 1.039.000 kişi engel olarak görmede zorluk yaşayanlar grubuna girmektedir. 2011 yilında Apple tarafindan duyurulan Siri' den, Siirt Zübeyde Hanım Mesleki ve Teknik Anadolu Lisesi öğrencilerinin "TÜBİTAK 4006 Bilim Fuarı Sergisi" kapsamında tasarladığı sensörlü bastona kadar yapay zekâ yardımı ile görme engellilere yardımcı olabilecek birçok ürün ve yazılım tasarlanmıştır. Mevcut çalışmada, görme engellilerin kendi başına ilaç kullanabilmesi için bir uygulama geliştirilmiştir. Uygulamanın geliştirilebilmesi için her bir ilaç için 100 adet fotoğraf kullanılmıştır ve toplamda 10 sınıflı bir veri kümesi oluşturulmuştur. Bu verilere CNN, Adam, RMSProp, Adagrad, Nadam algoritmaları uygulanmıştır. En iyi sonucu veren optimizasyon algoritması olan Adam ile model geliştirilmiştir. $\mathrm{Bu}$ çalışma da ise görme engelli bireyler için günlük hayatta kullanılan nesneler için eğitilmiştir (Yılmaz ve Gürhanlı, 2020).

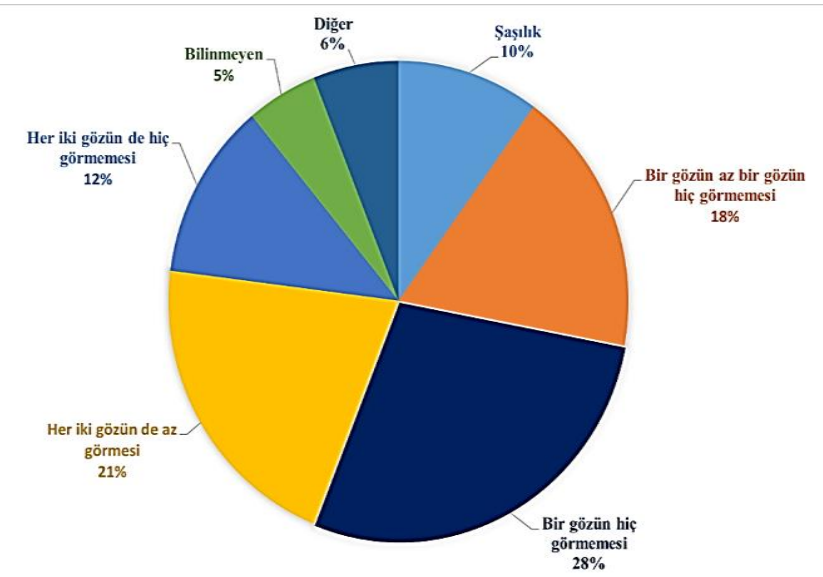

Şekil 2. Türkiye'de Görme Engelinin Türüne Göre Engelli Nüfus Orant.

"Facing Emotions" adlı proje yeni bir programlama dili ile geliştirilmiştir. Bunun sayesinde, insan bedenine bir elektronik alet ile takılabilen telefon, yüz tanımlama teknolojisi kullanarak arka kamerası ile yüzdeki ifadeyi, duyguyu sese dönüştürüp, görme engelli kişinin taktığı kulaklığa iletmektedir. İnsanların o anda karşı tarafa hissettirdikleri duyguya göre sesin analizini yapabilen bu uygulama ile, engelli bireyler için oluşabilecek engellerin bir kısmının ortadan kalkması için atılmış büyük bir adımdır. İleride bu çalışma için öngörücü bir bilgi olarak, sadece telefonlara değil, basit şekildeki kullanılabilir aparatlarla bu 
uygulama entegre şekilde çalıştırılabilir düşüncesi ortaya çıkmaktadır (Vizyoner Genç, 2021).

Son zamanlarda oldukça popüler olan, görüntü işleme uygulamalarını gerçek zamanlı çalışan sistemlerle yapmak önemli bir konuya dönüşmüştür. Görüntülerden nesnenin tespitini yapmada kullanılan görüntü işleme algoritmaları ile yapay zekânın alt dallarından biri olarak bilinen derin öğrenme, entegre bir şekilde kullanılarak, otonom insansız hava araçları, otonom kara araçları, yaşlı ve engelli bireyler için asistan teknolojileri, yardımcı robot teknolojileri gibi birçok alanda uygulamalar geliştirilmektedir. Görme engelli bireylere yardımcı olacak bir teknoloji ile gerçekleştirilen bu çalışmada ise, dokunsal parke yüzeylerinin tespiti için derin öğrenme yöntemlerinden yararlanılmıştır. Onlara yardım etmek amacıyla, bu çalışmada, dış mekân senaryolarında olası engellerin konumunu belirleyebilecek bir sistem önerilmektedir. Yaklaşımımız müdahaleci olmayan giyilebilir cihazlara dayanmaktadır ve aynı zamanda düşük maliyetli olmaya odaklanmaktadır (Bauer ve ark., 2020).

IoT ile gömülü derin öğrenme mekanizmasını kullanan akıllı perde asistanının, mimari tasarımını yansıtıyor. Önerilen model, derin öğrenme paradigmasının yanı sıra raspberry pi ve kamera modülünü kullanan akıllı bir kapak sunmaktadır. Önerilen model, çok sensörlü bir mikro denetleyiciyi kullanan akıllı bir görme engelli bastonunun yapısal tasarımını sunmaktadır. Taslak ayrıca tam entegrasyonun yöneticisi olarak hareket eden bir sanal asistan geliştirme süreci sağlamaktadır. Model, anlık veri izleme için IoT ve Bluetooth bağlantısını kullanır ve yetkili kişi, IoT bulut sunucusunu kullanarak görme bozukluğunu izlemeye devam eder. $\mathrm{Bu}$ beklenen modelin yeterliliğini incelemek için derin öğrenme kullanarak nesne algılama, sensör veri hesaplama ve sistem kullanılabilirliği numaralandırılır ve yorumlanır. IoT ile nesneler daha kullanışlı hale getirilir ve engelli bireyler için faydalı projelerin ortaya çıkarılması sağlanır (Rahman ve ark., 2021).

Sreeraj vd. yaptığı çalışmada; VIZIYON, engelleri uygun maliyetli bir şekilde belirlemek için IoT sistemine dayanan bir cihazdır. $\mathrm{Bu}$ cihaz, tanımlama, mesafe vektörü ve nesne algılamaya dayalı olarak işlemleri gerçekleştirir. Nesne tanıma, evrişimli sinir ağı kavramı kullanılarak yapılır. VIZIYON, nesnelerin mesafesini kullanırken, bu çalışmada ise ekranı dokuz parçaya ayırıp lokasyon belirlemesi yapılmaktadır. Bunlar, sağ, orta, sol, sağ alt, sağ üst, sol alt, sol üst, orta alt ve orta üst kısımlarıdır (Sreeraj ve ark., 2020). Bu çalışma, daha kolay ve etkili kullanıcı navigasyonu sağlayan verimli bir sistem tasarımı yoluyla kullanıcının dijital ara yüzlerle (örneğin kişisel bilgisayarların ve akıllı telefonların görüntüleme sistemi) deneyimini artırmayı amaçlamaktadır. $\mathrm{Bu}$ uygulama cep telefonlarına uyarlanabilir (Sait ve ark., 2020).

Literatürde, Çınar vd yaptığı çalışmada; logo tanıma uygulaması ile görme engelli bireyin akıllı telefonuna, geliştirilmiş bu uygulama indirilir. Gittiği bir alışveriş merkezinde yeme-içme katına, yemek yemek için çıkan görme engelli bireyin, bu katta hangi yemek firmalarının olduğunu ve bunların, bulunduğu konuma göre hangi yönde olduğunu bildiren bir uygulama geliştirilmiştir. Bu çalışma da bu uygulamada olduğu gibi telefon üzerinden ilerlemektedir. Konum ve seslendirme işlemleri yapılmıştır. Görme engelli birey telefonundaki uygulamayı açar, kamerayı çalıştıran bu uygulama ile çevresini tarar, elde edilen canlı görüntüden resimleri ayırt eder ve uygulamanın gönderdiği resimde yer alan tüm şirket logolarının tespiti yapılır. Bu logoların sahip olduğu şirket isimleri bu uygulama yardımıyla seselendirilip kullanıcıya iletilir. Böylece görme engelli birey, etrafındaki yemek firmalarının neler olduğunu ve kendi konumuna göre yönlerini kimseden yardım almadan öğrenmiş olur (Atılım Üniversitesi, 2021).

$\mathrm{Bu}$ çalışmada, öncelikle yapay sinir ağlarından, makine öğrenmesi ve derin öğrenme yöntemlerinden ve gerçek zamanlı nesne tespiti yapabilen algoritmalardan biri olan YOLO algoritmasından bahsedilecektir. Ayrıca grafiksel ara yüzlerin tasarlanmasını ve oluşturulmasını sağlayan Qt Designer konusu ele alınacaktır. Nesnelerin tanınması için nesnelerin eğitim ve test kısmı yapılacaktır. Eğitilen nesnelerin kamera aracılığıyla alınıp, arka planda eğitilen model sayesinde tanımlanıp, konumunu bularak, seslendirilmenin nasıl yapılacağından bahsedilecektir.

\section{Materyal ve Metot}

\subsection{Yapay Sinir Ağları}

Teknolojinin gelişmesi göz önünde buludurulduğunda, önceleri karmaşık hesaplamaları yapmak, sadece elektronik veri transferleri gerçekleştirmek üzere geliştirilmiş bilgisayarların günümüzde ise, büyük miktarlardaki verileri filtreleyip özetleyebilen ve eldeki bilgileri kullanıp olaylar hakkında yorum yapabilen duruma geldikleri görülmüştür. Bu çalışmaların özüne bakıldığında ise bilgisayarlar, yüzyıllar boyunca insan beyninin nasıl işlediğinin merakı sonucu ortaya çıkmış, ilkel hesaplama makinelerinin geliştirilmiş versiyonudur. Teknoloji ilerledikçe insanlar, bilgisayarların işlemleri hızlı yapması gibi, önceki temel düşüncelerinden çok, bu teknolojiden elde edecekleri yararı önemsemeye başlamışlardır. Bazı uzmanlar ise, yapay zekâ bilimi başta olmak üzere, çalışmalarını insan davranışlarının modellenmesi yolunda devam ettirmiş olup, bununla çok önem arz eden gelişmeler ortaya koymuşlardır (Öztemel, 2012).

Yapay sinir ağları, yapay zekâ alanındaki çalışmalarının hızını önemli oranda artırmıştır. $\mathrm{Bu}$ da makine öğrenmesinin gelişmesine önemli katkıları olan bir teknoloji olarak görülmüştür. Sanayi toplumunun bitmesi ve sonrasında bilgi toplumunun başlamasına sebep olan etkenlerden biri de yapay sinir ağları olmuştur. Yapay sinir ağları, bir olayın örnekleri ile eğitilip, onunla ilgili olaylar hakkında genelleme yapabilmekte, bilgiler toplayabilmekte ve daha sonra hiç karşılaşmadığı örnekleri görünce, öğrendiği bu bilgileri kullanarak, o örnekler hakkında karar verebilme yetisine sahip olabilmektedir. Yapay zekâ algoritmaları, büyük miktarda veriyi işleme ve geleneksel yaklaşımlar kullanılarak tespit edilemeyen kalıpları ve özellikleri tespit etme gibi yeteneklere sahiptirler (Luckey ve ark., 2020).

Yapay sinir ağlarının ortaya nasıl çıktığından bahsedecek olursak; insan ve insanın düşünme yapısı örnek alınmıştır. İnsanların yaptığı, yorumladığı, anlamlaştırdığ bilgisayar kendisi yapmaya başlamıştır. Yapay sinir ağlarının kullanıldığ 1 alanlardan bahsedecek olursak; görüntü işeleme, ses ve görüntü tanıma, sistem ve kontrol tanımlama, arıza analizi yapma, kestirim ve tahmin etme, haberleşme, mühendislik uygulamaları, tıp, trafik, eğlence amaçlı tahmin ve üretim yönetimi olarak kullanılır (Derin Öğrenme, 2017). 
Tablo 1. Geleneksel Algoritmalar ile Yapay Sinir A $\breve{g l}$ Algoritmalarının Karşılaşıtırılması.

\begin{tabular}{|l|l|}
\multicolumn{1}{|c|}{ Geleneksel Algoritmalar } & \multicolumn{1}{|c|}{ Yapay Sinir Ağları } \\
\hline $\begin{array}{l}\text { Girişlerin koyulan kurallara } \\
\text { uygulanması ile çıkışlar elde } \\
\text { edilir. }\end{array}$ & $\begin{array}{l}\text { Kurallar, öğrenme sırasında } \\
\text { giriş-çıkış bilgileri verilerek } \\
\text { koyulur. }\end{array}$ \\
\hline Bilgi ve algoritmalar kesindir. & Deneyimden faydalanılır. \\
\hline $\begin{array}{l}\text { Hesaplama işlemi; ardışık, eş } \\
\text { zamanlı ve merkezidir. }\end{array}$ & $\begin{array}{l}\text { Hesaplama işlemi; eş } \\
\text { zamansız, toplu ve } \\
\text { öğrenmeden sonra paraleldir. }\end{array}$ \\
\hline $\begin{array}{l}\text { Hazır bilgi depolanmış ve } \\
\text { bellek paketlenmiştir. }\end{array}$ & $\begin{array}{l}\text { Bellek ayrılmış olup ağa } \\
\text { yayılmış şekildedir. }\end{array}$ \\
\hline Hata toleransı sıfırdır. & $\begin{array}{l}\text { Hata toleransı bulunur. } \\
\text { Konanıma bağımlı ve } \\
\text { yavaştır. }\end{array}$ \\
\hline
\end{tabular}

Yapay Sinir Ağlarının temel ayrımları vardır. Bunlar:

- Öngörü ve Tahminleme

- Siniflandirma ve Kümeleme

- Kontrol

Yapay sinir ağı, tek hücreden de oluşabilmekte, birçok hücrenin birlikte bulunduğu katmanlardan da oluşabilmektedir. Geri beslemeli, Çok Katmanlı Algılayıcı (ÇKA), Tek Katmanlı Algılayıcı (TKA), ADALINE / MADALINE gibi lineer ve lineer olmayan sistemler için geliştirilmiş birçok farklı YSA modeli bulunmaktadır (Metlek ve Kayaalp, 2021).

Bir yapay sinir ağı hücresi Şekil 3 'te olduğu gibi, temel olarak girdi değerlerinden, ağırlıklardan, toplama fonksiyonu, aktivasyon fonksiyonu ve çıktıdan oluşmaktadır.

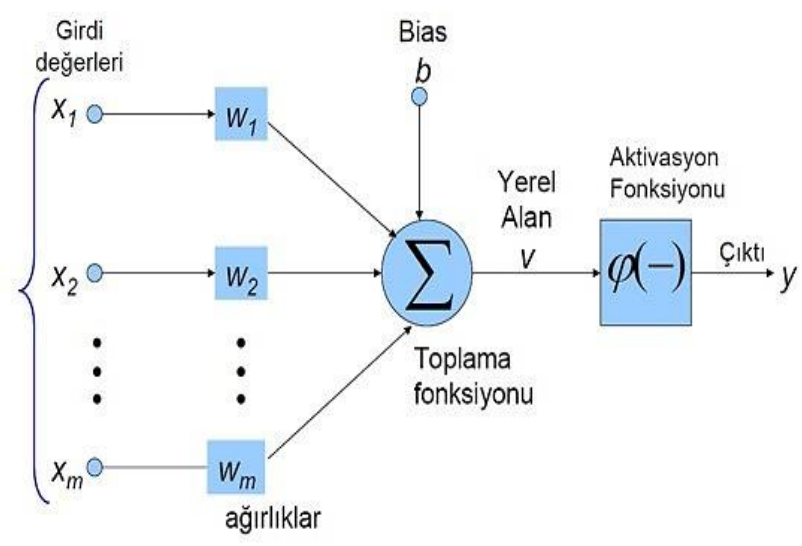

Şekil 3. Yapay Sinir A $\breve{g}$ l.

\subsection{Makine Öğrenimi}

Makine öğrenmesi yapısal ve işlevsel olarak öğrenmeye açık, yorumlama yeteneğine sahip, verileri anlayarak sonuçlar ya da çıktılar ortaya koyan bir sistemdir. Kendilerine bir model oluşturarak çalışmaktadır. Belli bir algoritmaya göre giriş verilerini verip, çıkış parametresiyle istatistiksel tahminler de bulunarak doğru tahmin etmeye çalışan bir öğrenimdir. Makine öğreniminin önemli olmasının sebeplerinden bazıları; Bayes analizinin her zamankinden daha fazla tercih edilir olmas1, makine öğrenimine olan ilginin artması ve veri madenciliğinden kaynaklanmaktadır. Veri çeşitlerinin ve hacimlerinin artması, daha ucuz ve güçlü olan hesaplamalı işlemlerin yapılması ve ekonomik olarak verilerin depolanması gibi durumlar makine öğreniminin öneminin artmasına sebep olmuştur (SAS, 2021).
Tüm bu durumlarda, daha karmaşık ve büyük verilerin analiz edilmesi ve büyük ölçekli verilerde bile, daha doğru ve hızlı sonuçlar verebilen modelleri otomatik olarak işeleme olanağ bulunmaktadır. Ayrıca bu durumun hızlı bir şekilde üretmenin mümkün olduğu anlamına gelmektedir. Bu modeller sayesinde firmaların ekonomik firsatları ortaya koyma veya belirsiz risklerden korunma şansı daha fazla artmaktadır.

Makine öğreniminin bir dalı olan derin öğrenme, bir dizi algoritmaya dayanmaktadır. Verilerde bu öğrenme algoritmaları, üst düzey soyutlamayı modeller. Birçok doğrusal ve doğrusal olmayan dönüşümden oluşan çeşitli işleme katmanlarıyla derin grafiği kullanılır. Örüntü tanıma süreci ve veri sınıflandırmasının uzun süreden beri değerli olduğu bilinmektedir.

İnsanlar çevreyi algılamak için çok güçlü bir yeteneğe sahiptir. Çevreden algıladıklarına karşı harekete geçer. Büyük veri, makine öğrenimi, veri tabanları ve istatistiklerin çok disiplinli tümleşik yapısı nedeniyle parçalara dönüşür (Fatima ve Pasha, 2017).

\subsubsection{Makine Öğrenimi Terimleri}

4 temel makine öğrenmesi terimi vardır. Bunları açıklayacak olursak;

a) Denetimsiz Öğrenme

Verilerden çok az bilgiye sahip olunduğunda ya da veriler hakkında herhangi bilgiye sahip olunmadığında kullanılan yöntemdir. Kesinlikten bahsedilemez.

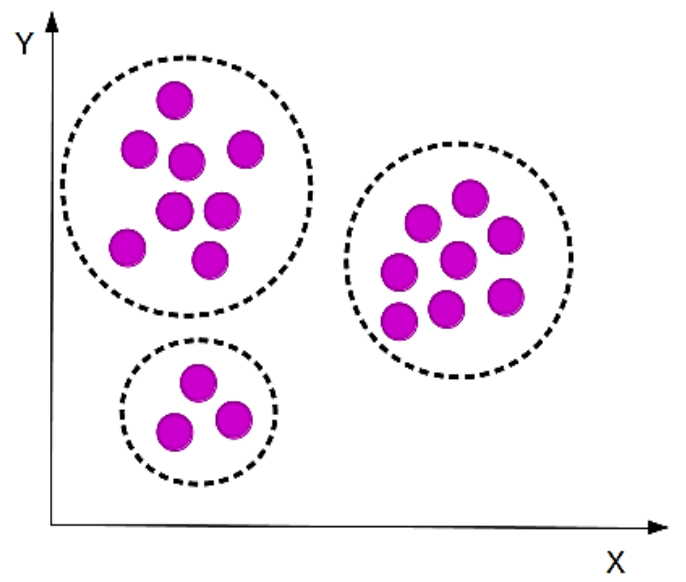

Şekil 4 Denetimsiz öğrenme

Denetlenmeyen öğrenmeye örnek olarak:

- Kümeleme (Clustering)

- Anomali Tanıma

- Sinir Ağları

- Gizli Değişken Model Öğrenme Yaklaşımları.

Makine öğrenmesindeki yaklaşımların diğerlerinden farklı olarak, önceki tecrübelerine dayanan kendi yanlılı̆̆ı ile öğrenir. Ayrıntılı olarak geliştirilen öğrenme durumlarının kendi sırasını üretir, bu da otonom olarak kendini keşif ve insan desteği ile kümülatif olarak yeni becerileri kendi modeline ekler. Makine öğrenmesi algoritmalarına örnek olarak;

1. Karar Ağaçları Öğrenmesi

2. Birliktelik Kuralı

3. Yapay Sinir Ağları

4. Derin Öğrenme

5. Destek Vektör Makineleri

6. Kümeleme

7. Bayes Network

8. Genetik Algoritmalar 


\section{b) Denetimli Öğrenme}

Veri kümesinde neler olduğunu bilip ona göre çıtılar beklediğimiz öğrenme yöntemidir. Problem, sürekli çıktılar ile gözlemlenerek çözülür.

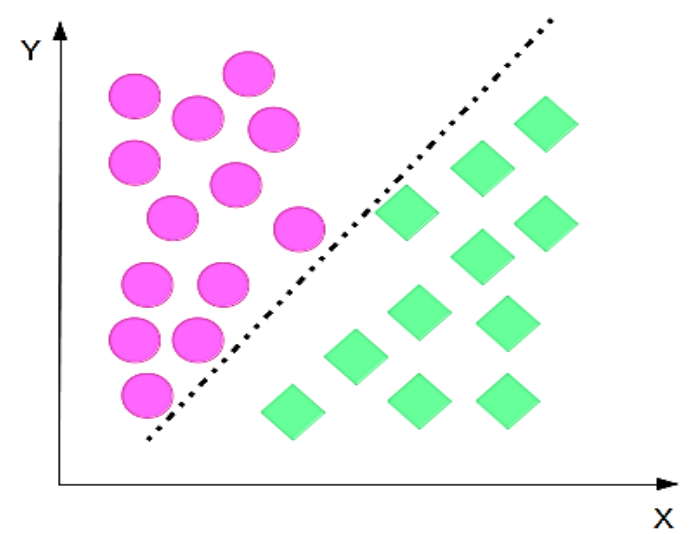

Şekil 5. Denetimli Öğrenme.

\section{c) Yarı Denetimli Öğrenme}

Etiketlenmiş veri ile etiketlenmemiş verinin birlikte kullanılmasidır.

d) Takviyeli Öğrenme

Öğreticinin, üretilen sonuç ile doğru ya da yanlış tahmin demesiyle oluşturulan öğrenme şeklidir.

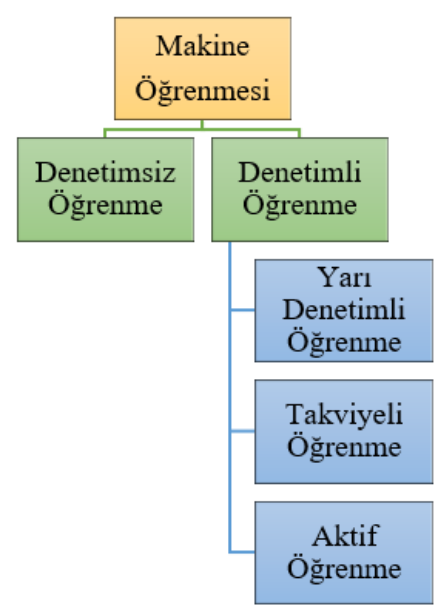

Şekil 6. Makine Öğrenmesi Yaklaşımları Şeması.

Makine öğrenmesi, problemlerin yaklaşımlarına göre farklılık gösteren çözümler üretmektedir. Bu öğrenme yaklaşımları denetimli öğrenme ve denetimsiz öğrenme olarak iki alt kategoride incelenir. Bu kategoriler Şekil 7' deki gibi alt başlıklara ayrılmaktadır.

\subsubsection{Makine Öğrenimi Kullanım Alanları}

Makine öğrenmesi yaklaşımı açık bir şekilde programlanan algoritmaların büyük işlemler ve veriler üzerinden yeterince performans vermediği durumlarda kullanılır. A $\breve{g}$ analizleri, spam mail araştırmaları, optik karakter tanımlamaya benzer yüksek işlem gücü gerektiren alanlarda kullanılmaktadır. Matematiksel optimizasyon ve teorik hesaplamalarla oldukça yakından ilişkileri olan bilgisayar tabanlı istatistik modellerini içinde barındıran disiplinler arası bir çalışma şekli olan makine öğrenmesi daha çok veri madenciliği alanlarıyla bağlantılıdır. Lojistik, tedarik, üretim ve taşıma alanında; üretimin hızını arttırmak, robotların kollarını eğitmek ve işlemleri daha verimli hale getirmek için endüstriyel sınıfa giren araçların otomatize edilmesi, gelişmiş incelemeleri yapmak için mikroskopların otomatize edilmesi, Amazon ve Netflix gibi platformların kullanıcı taleplerine göre kaynak dağılımının optimize edilmesi, ERP/ERM (Kurumsal kaynak planlaması) uygulamaları, kalite güvencesinin geliștirilmesi, hangi ürünlerden hangi saatlerde daha çok satılabileceği konusunda tahminlerin yapılabilmesi, cihaz bakımının veya arızasının tahmin edilmesi, üretim performansının arttırılması için satış ve pazarlama gibi birimlerde kullanımı, yapay zeka ile geliştirilen asistanlar ile satış görevlerini otomatikleştirme (Fusemachines), satış için elde edilecek firsatları tahmin etmeye ve bu görevleri otomatik olarak yapmaya yardımc1 olma (Salesforce Einstein), halkla ilişkiler açısından elde edilecek performansları artırmak için öngörü sağlama (AirPR), müşteri bölümlemesinin doğruluğunu yükseltme ve bir müşteri açısından ömür boyu değerini tahmin etme gibi amaçlarla kullanılabilir. İnsan kaynakları alanında işverenlerin, adayları vasıflarına göre ayırma ve bunları tanımlamada yardımcı olurken, yöneticilere ise yetenek yönetimi konusunda yardımcı olmaktadır (Derin Öğrenme, 2021).

Finans alanında ise, yapay zekâ ile çalışan uygulamalarla yatırım açısından yönetim kararlarını güçlendirmekte (Cerebellum Capital, Sentient), şok gelişmeler ve sosyal yönelimler hakkında daha önceden uyarılar vererek gerçek zamanlı finansal kararların alınmasına yardımcı olmaktadır (Dataminr). Ayrıca hisse senetlerinin fiyatın tahmin etmek ve sahtekarlıkları tespit etmek amacıyla da insanlara fayda sağlamaktadır.

\subsection{YOLO Algoritması}

En hızlı şekilde gerçek zamanlı nesne tespiti yapabilen bir algoritma olarak 2017 yılında ortaya çıkmıştır. Diğer algoritmalara göre hızlı ve doğruluk oranı yüksek bir algoritmadır. Diğer algoritmalarda, gerçek zamanlı nesne tespiti yapmaktadır, fakat YOLO algoritmasının ortalama kesinlik değeri yüksektir. YOLO, nesne algılama için evrişimli sinir ağlarını kullanan bir algoritmadır. Tanıma algoritmalarına kıyasla, bir algılama algoritması yalnızca sınıf etiketlerini öngörmekle kalmaz, aynı zamanda nesnelerin konumlarını da algılar. YOLO algoritmasının diğer algoritmalardan farkı, evrişimli model kullanarak, veriyi daha hızlı işlemesidr. YOLO algoritmasında sıkça kullanılan, $\mathrm{COCO}$ veri setidir. Bu veri seti ile yapılan çalışmada, büyük nesnelerde $\% 98$ başarı oranı sergilerken, daha kü̧̈ük nesnelerde başarı oranının $\% 60$ civarında olduğu ortaya konulmuştur. Derin öğrenme yöntemlerinden olan evrişimli ağ temelli model görüntü işleme de kullanılırken ve YOLO (You only look once) ve benzeri algoritmaların nesne tespiti yönteminde kullanıldığı gözlenmiştir (TÜBAV, 2020).

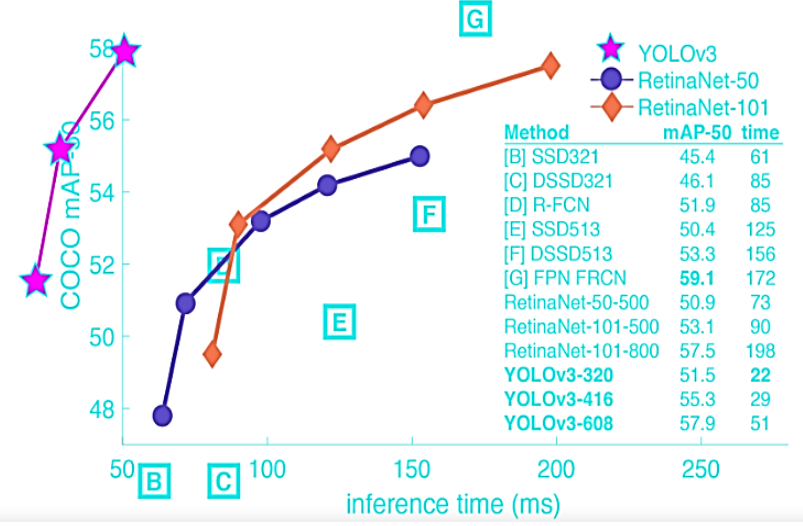

Şekil 7. YOLOv3 ve Diğer Algoritmalar. 
YOLO algoritmasının diğer algoritmalardan hızlı olmasının sebebi, girdinin sadece bir kez nöral ağdan geçerek, çıktının sınıfını ve kordinatlarını tahminlemesidir.

\subsection{COCO’ da YOLO Eğitimi}

YOLO algoritması, modeli eğitmek için kullanılır. COCO ise veri setini indirmek için kullanılmıştır. COCO verilerinin eğitiminin tamamlanması aşağıda aşamalar ile anlatılmıştır (Pjreddie, 2021).

\section{Aşama: Darknet Kurulumu}

YOLO algoritmasının çalışması için gerekli kütüphanedir. Bash ubuntu terminali üzerinden aşağıdaki komutlar sırasıyla çalıştırılır.

git clone https://github.com/pjreddie/darknet

cd darknet

make

COCO verilerinin bulunacağı dosyayı belirlemeye ve indirmeye yarayan komutlar.

cp scripts/get_coco_dataset.sh data

cd data

bash get_coco_dataset.sh

2.Aşama: COCO için config dosyasını değiştirme

Darknet dizinindeki cfg/coco.data yapılandırma dosyasını verileri aşağıdaki gibi değiștirilmelidir.

$$
1 \text { classes }=80
$$

2 train $=\langle$ path-to-coco $>/$ trainvalno $5 \mathrm{k} \cdot \mathrm{txt}$

3 valid $=\langle$ path-to-coco $>/ 5 \mathrm{k} \cdot \mathrm{txt}$

4 names $=$ data/coco.names

5 backup = backup

<path-to-coco> COCO verilerinin bulunduğu dizin değiştirilir.

Ayrıca test için cfg modeli de değiştirilmelidir. cfg/YOLO.cfg şeklinde olmalıdır.

[net]

\# Testing

\# batch=1

\# subdivisions $=1$

\# Training

batch $=64$

subdivisions $=8$

\section{Aşama: Modelin Eğitim Aşaması}

/darknet detector train cfg/coco.data cfg/YOLOv3.cfg darknet53.conv.74

\section{Așama: Verisetinin test edilmesi}

Eğitim için Imagenet üzerinde önceden eğitilmiş konvolüsyonel ağırlıklar kullanılır. Darknet53 modelindeki ağırlıklar kullanılacaktır.

Wget,https://pjreddie.com/media/files/YOLOv3openimages.weights

./darknet detector test cfg/openimages.data cfg/YOLOv3openimages.cfg YOLOv3-openimages.weights

\subsection{Ara Yüz Tasarımı}

Qt Designer, grafiksel ara yüzlerin tasarlanması ve oluşturulması için kullanılan programdır. $\mathrm{Bu}$ uygulamanın ara yüzü bu program ile tasarlanmıştır (Karahasan, 2021). Qt Designer ile oluşturulan widget'lar ve formlar, Qt'nin sinyallerini e-ISSN: 2148-2683 ve yuva mekanizmasını kullanarak programlanmış kodla sorunsuz bir şekilde bütünleşerek grafiksel öğelere kolayca davranış atanabilir. Qt Designer'da ayarlanan tüm özellikler, kod içinde dinamik olarak değiştirilebilir. Ayrıca, widget tanıtımı ve özel eklentiler gibi özellikleri, Qt Designer ile kendi bileşenlerinde de kullanmaya olanak tanımaktadır (Q Designer, 2021).

\section{6. Önerilen Model}

$\mathrm{Bu}$ çalışmada geliștirilen modelde kamera aracılığıyla yapılacak işlemlere başlanılmaktadır. Kamera açılmasıyla görüntü yakalanır ve görüntünün hangi nesne olduğunu bulması için nesne algılama yapılır. Nesne, eğitilen modeller arasında ise nesneyi işaretler ve nesnenin konumunu tespit eder. Bu konumu seslendirerek konuşmaya dönüştürür. Eğer nesne algılama da sıkıntı oluşmuş ise tekrar görüntü araması yapmaktadır. Böylece görme engelli bireylere etrafindaki nesneleri seslendirip konumunu vererek yardımcı olan bir model geliştirilmiştir.

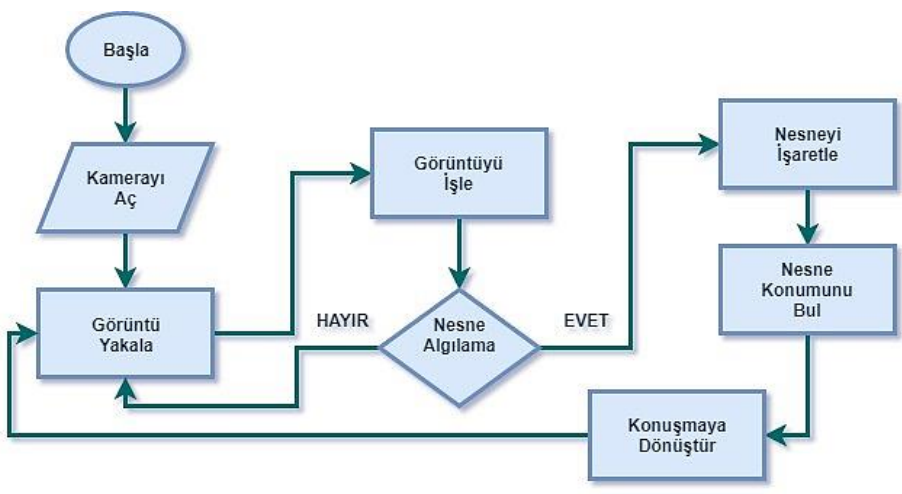

Şekil 8. Önerilen Modelin Akış Diyagramı.

\section{BULGULAR VE TARTIŞMALAR}

Programın çalışması için terminale aşağıdaki komut satırı uygulandığında gerçek zamanlı nesne tanıma programı başlayacaktır.

1.Adım: C:IYOLO\python eye.py

Program çalıştırıldığında Şekil 9' da olduğu gibi nesneler gösterildiğinde, eğitilmiş model ile tanıma işlemi yaparak seslendirme olacaktır.

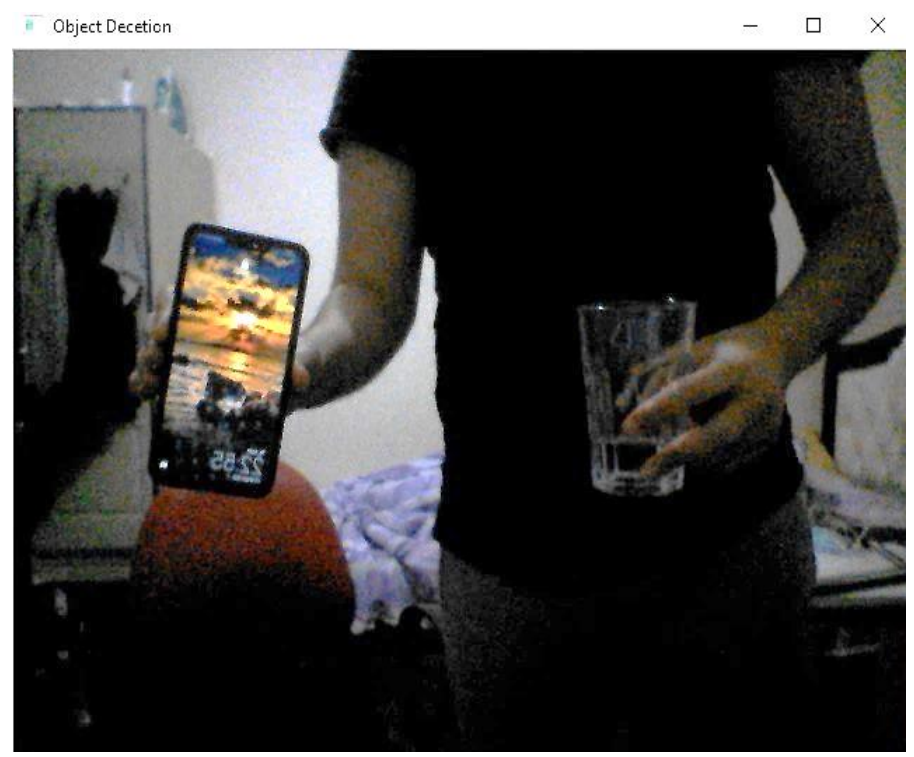

Şekil 9. Nesne Tanıma. 
2.Adım: Program çalışırken seslendirdiği nesneler Şekil 10’ da olduğu gibi terminal de gösterilmektedir.

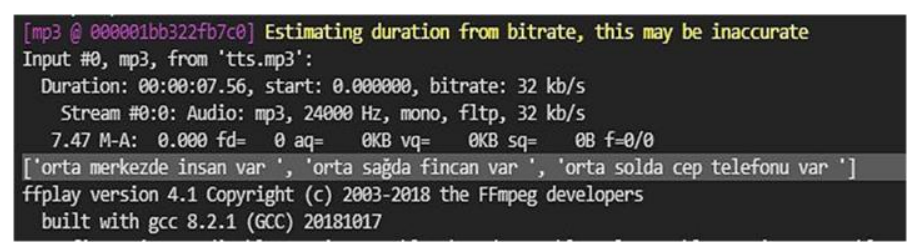

Şekil 10 Terminalde Seslendirilen Nesnelerin Yazıldı̆̆ Ekran.

3.Adım: Programı başlatmak ve ekranda kodların görünmemesini sağlamak için ara yüz tasarlanmıştır.

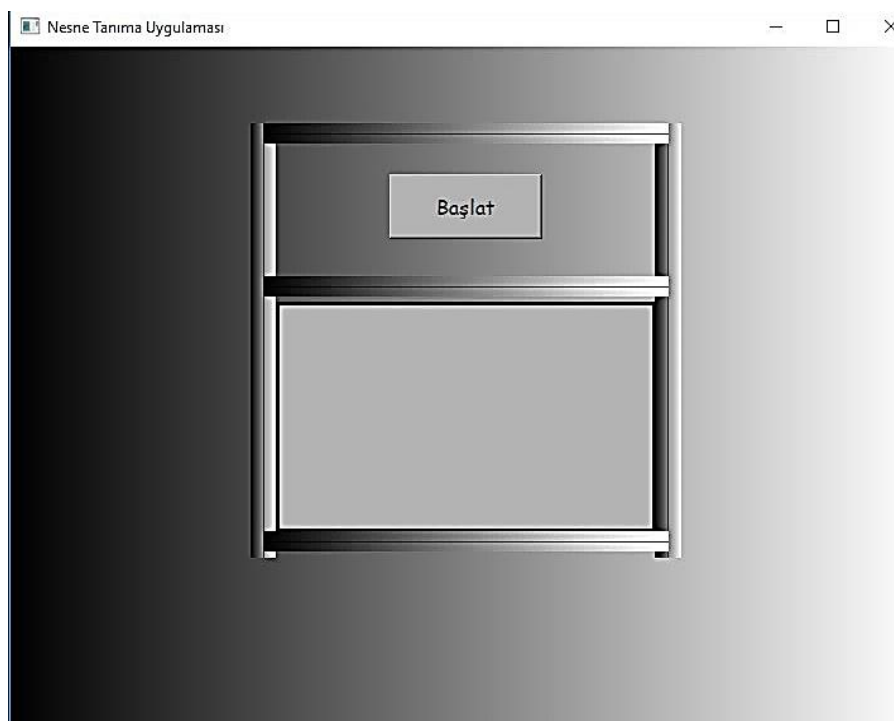

Şekil 11. Uygulama Ara Yüzü.

4.Adım: Ara yüz programı çalıştırılarak Şekil 12 ve Şekil 13' deki gibi görüntüleri seslendirerek görme engelli bireylere yardımcı olan bir uygulama geliştirilmiştir.
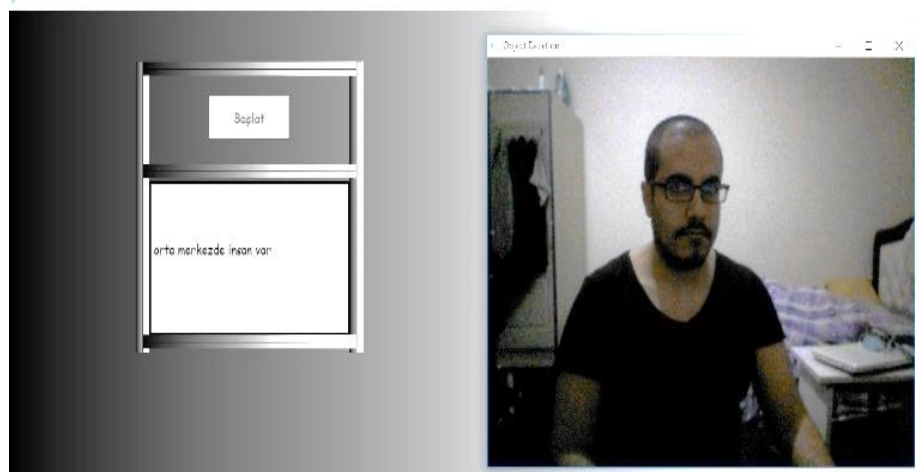

Şekil 12. Ara Yüz Çalışma Örneği-1.

Geliştirilen uygulama sayesinde görme engelli bireylerin etrefından olan cisimleri tanımasına imkân verilmektedir. Bu çalışmada geliştirilen uygula tamamen orijinal bir çalışma olup tüm resimler bu çalışmada verilmiştir.

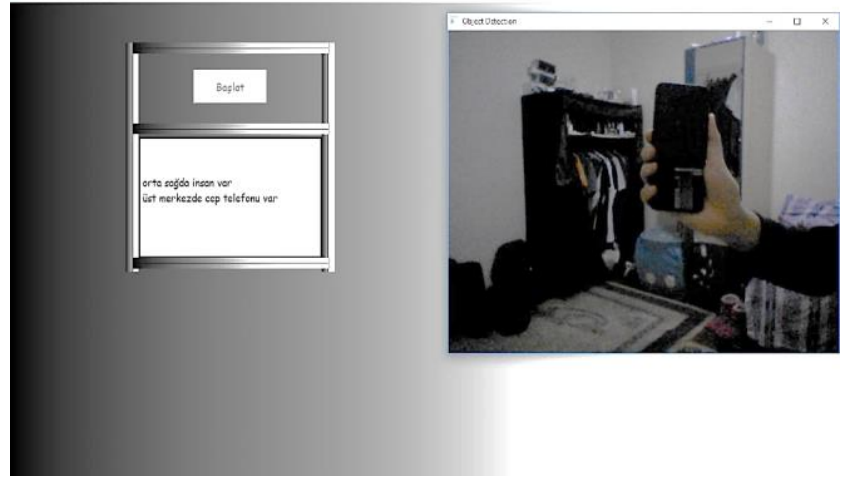

Şekil 13. Ara Yüz Çalışma Örneği-2.

\section{Sonuç}

Bu çalışmada, YOLO ile gerçek zamanlı nesne tanıma işlemi yapılmıştır. Eğitilen nesneleri seslendirerek görme engelli bireylere gerçek hayatta yardımc1 olacak bir uygulama geliştirilmiştir. Bu uygulama ile görme engelli bireylerin yaşam standartları iyileşecek ve yanında bir başkası olmadan dışarıya çıkmaya başlayacaklardır. Çünkü bu uygulama görme engelli bireylere yol gösterecek ve telefonlarına indirerek bu uygulamaya sahip olmaları mümkün olacaktır. Bu araştırmada, görme engelli bireyler için günlük yaşantılarında kolaylık sağlayacak bir uygulama ile, etrafindaki nesneleri tanımlayacak, bu nesneleri seslendirecek, dışarıdan herhangi birine ihtiyaç duymadan yürümelerine ve hayatın akışının onlar için daha kolay olmasına olanak sağlayacak bir proje gerçekleştirilmiştir.

$\mathrm{Bu}$ geliştirilen uygulama ile görme engelli bireylerin günlük hayatta sık olarak kullandıkları nesneleri bulmada daha rahat etmeleri ve başına gelebilecek kazaların azaltılması sağlanmışır. $\mathrm{Bu}$ proje ile görme engelli bireylerin hayatında kolaylık sağlanması hedeflenmektedir. Yapılan çalışmada, geliştirilen model 81 adet nesneyi tanıyor iken, modelin geliştirilmesi ile neredeyse hayatımızda bulunan tüm nesneleri tanıyor hale getirilmesi ön görülmektedir. Ayrıca yanımızda taşıyabileceğiz her türlü teknolojik cihazlara bu uygulamanın entegre edilmesi hedeflenmektedir.

$\mathrm{Bu}$ çalışmada konum belirleme adımı, ekranı dokuz parçaya bölerek yapılmaktadır. Bunlar sağ, orta, sol, sağ alt, sağ üst, sol alt, sol üst, orta alt ve orta üst olacak şekilde tasarlanmıştır. Bu proje de YOLO gerçek zamanlı nesne tanıma yapılmışıtır. Hazırlanan veri seti etiketlenmiş ve YOLO algoritması kullanılarak test aşaması gerçekleştirilmiştir. Etiketlenen verilerin doğruluğunun tespit edilmesi için, nesne tanıma işlemi yapılmıştır. YOLO algoritmasının tercih edilmesinin sebebi gerçek zamanlı nesne tanıma işleminde diğer algoritmalara göre daha hızlı olması ve küçük objelerin tespitinde daha doğru sonuç vermesinden kaynaklanmaktadır.

Sonuç olarak bu çalışmada, kameradan görüntüyü alıp işleyerek, oluşturulan model ile kameradan alınan nesneyi tanımlayıp, konumunu belirleyip, bunları seslendiren ve görme engellilerin hayatını kolaylaştıracak bir proje geliştirilmiştir. Böylece bu alanda yapılacak çalışmalara örnek olacak bir akademik çalışma yapılmış olması hedeflenmiştir. Bu alanda yapılacak çalışmaların desteklenerek görme engelli bireyler için hayatı kolaylaştıracak uygulamaların geliştirilmesi teşvik edilmelidir. Bundan sonraki çalışmlarda daha farklı yapay sinir ağı modelleri ve farklı veri setleri kullanılarak başarım oranındaki değerlerin karşılaştırılması yapılabilir. Ayrıca bu çalışmalar farklı alanlarda yapılarak sosyal hayatı kolaylaştırıcı uygulamalar geliştirilebilir. 


\section{Kaynakça}

At1lım Üniversitesi. (2021) http://user.atilim.edu.tr/ murat.karakaya/projects/Logo $\% 20$ Tanima.pdf (Erişim tarihi: )

Bauer, Z., Dominguez, A., Cruz, E., Donoso, F. G., Escolano, S., Cazorla, O. M. (2020). Enhancing perception for the visually impaired with deep learning techniques and lowcost wearable sensors. Pattern Recognition Letters, 137, 27 36.

Derin Öğrenme. (2017). https://www.derinogrenme.com /2017/03/04/yapay-sinir-aglari. (Erişim tarihi: 22.08.2021)

Derin Öğrenme. (2021) https://www.smartmind.com.tr/yapayogrenmenin-machine-learning-kullanim-alanlari-i-930. (Erişim tarihi: 12.08.2021)

Fatima, M., Pasha, M. (2017). Survey of machine learning algorithms for disease diagnostic, Scientific Research, 9 (1), 1-16.

Karahasan, B. (2021) Pyqt nedir? qt designer nedir? python arayüz tasarımı. https://birhankarahasan.com/pyqt-nedir-qtdesigner-nedir-python-arayuz-olusturma. (Erişim tarihi: 21.08.2021)

Luckey, D., Fritz, H., Legatiuk, D., Dragos, K., Smarsly, K. (2020). Artificial Intelligence Techniques for Smart City Applications. Springer, 98, 3-15.

Metlek, S., Kayaalp, K. (2021). Detection of bee diseases with a hybrid deep learning method, Journal of the Faculty of Engineering and Architecture of Gazi University, 36 (3), 1715-1731.

Mevlâna Kalkınma Ajansi. (2021) https://www.mevka.org.tr/Yukleme/Uploads/Dsyahvsky10 282019100107AM.pdf (Erişim tarihi: 18.08.2021)

Özkaya, U., Öztürk, Ş., Melgani, F., \& Seyfi, L. (2021). Residual CNN+ Bi-LSTM model to analyze GPR B scan images. Automation in Construction, 123, 103525.

Öztemel, E. (2012). Yapay sinir ağları. Rifat Çölkesen, Papatya Yayıncilık, İstanbul.

Pjreddie. (2021) YOLO: Real-Time Object Detection. https://pjreddie.com/darknet/YOLO. (Erişim tarihi: 27.08.2021)

Qt Designer Manual. (2021) https://doc.qt.io/qt-5/qtdesignermanual.html. (Erişim tarihi: 28.08.2021)

Rahman, W., Tashfia, S.S., Islam, R., Hasan, M., Sultan, S., Mia, S., Rahman, M. M. (2021). The architectural design of smart blind assistant using IoT with deep learning paradigm. Internet of Things, 13.

Sait, U., Ravishankar, V., Kumar, T., Bhaumik, R., Lal, G., Bhalla, K., Sanjay, K. S. (2020). Design and development of an assistive device for the visually impaired. Procedia Computer Science, 167, 2244-2252.

Sas.(2021)https://www.sas.com/en_us/insights/analytics/machin e-learning.html. (Erişim tarihi: 22.08.2021)

Sreeraj, M., Joy, J., Kuriakose, A., Bhameesh, M. B., Babu, A. K., Kunjumon, M. (2020). VIZIYON: Assistive handheld device for visually challenged. Procedia Computer Science, 171, 2486-2492.

Tübav, B. (2020). Real-time vehicle detection by using deep learning methods, Journal of the Faculty of Engineering and Architecture of Gazi University, 13 (3), 1-14.

Veri Gazeteciliği. (2021) http://www.verigazeteciligi.com/soloproje-turkiyede-gorme-engellilere-ozel-egitim-verensadece-17-ilkokul-var (Erişim tarihi:28.08.2021)
Vizyoner Genç. (2021) https://vizyonergenc.com/icerik/yapayzeka-gorme-engelliler-icin-engelleri-ortadan-kaldiriyor (Erişim tarihi:13.08.2021)

World Health Organization. Blindness and vision impairment. (2021). https://www.who.int/en/news-room/factsheets/detail/blindness-and-visual-impairment (Erişim tarihi:15.08.2021)

Yilmaz, O., Gürhanl1, A. (2020). The application of drug recognition based on artificial neural networks for visually impaired individuals. Yüksek Lisans Tezi, İstanbul Aydın Üniversitesi, Lisansüstü Eğitim Enstitüsü, İstanbul. 